\title{
Changes in primary care provider utilization by phase of care for women diagnosed with breast cancer: a CanIMPACT longitudinal cohort study
}

K. Decker ${ }^{1,2^{*}}$ (D, R. Moineddin ${ }^{3}$, C. Kendell ${ }^{4,5}$, R. Urquhart ${ }^{4}$, N. Biswanger ${ }^{1}$, P. Groome ${ }^{6}$, M. L. McBride ${ }^{7}$, M. Winget ${ }^{8}$, M. Whitehead ${ }^{6}$, E. Grunfeld ${ }^{3,9}$ and for the Canadian Team to Improve Community-Based Cancer Care Along the Continuum (CanIMPACT)

\begin{abstract}
Background: Primary care providers (PCPs) have always played an important role in cancer diagnosis. There is increasing awareness of the importance of their role during treatment and survivorship. We examined changes in PCP utilization from pre-diagnosis to survival for women diagnosed with breast cancer, factors associated with being a high user of primary care, and variation across four Canadian provinces.

Methods: The cohorts included women 18+ years of age diagnosed with stage I-III invasive breast cancer in years 2007-2012 in British Columbia (BC), Manitoba (MB), Ontario (ON), and Nova Scotia (NS) who had surgery plus adjuvant chemotherapy and were alive $30+$ months after diagnosis $(N=19,589)$. We compared the rate of PCP visits in each province across phases of care (pre-diagnosis, diagnosis, treatment, and survival years 1 to 4).
\end{abstract}

Results: PCP use was greatest during treatment and decreased with each successive survival year in all provinces. The unadjusted difference in PCP use between treatment and pre-diagnosis was most pronounced in BC where PCP use was six times higher during treatment than pre-diagnosis. Factors associated with being a high user of primary care during treatment included comorbidity and being a high user of care pre-diagnosis in all provinces. These factors were also associated with being a higher user of care during diagnosis and survival.

Conclusions: Contrary to the traditional view that PCPs focus primarily on cancer prevention and early detection, we found that PCPs are involved in the care of women diagnosed with breast cancer across all phases of care.

Keywords: Primary health care, Breast neoplasms, Clinical decision-making

\section{Background}

Breast cancer is the third most commonly diagnosed cancer in Canada and accounts for $13 \%$ of all cancers [1]. While the incidence of breast cancer has fluctuated, breast cancer mortality has decreased significantly in developed countries over the last 20 years [2]. In Canada, the breast cancer mortality rate decreased at least $44 \%$

\footnotetext{
* Correspondence: kdecker@cancercare.mb.ca

'CancerCare Manitoba, 675 McDermot Avenue, Winnipeg, Manitoba ROE 0V9, Canada

2University of Manitoba, 750 Bannatyne Avenue, Winnipeg, Manitoba R3E oW2, Canada

Full list of author information is available at the end of the article
}

since its peak in 1986 [1]. This has resulted in improved survival (Canadian five-year net survival between 84 and $88 \%$ ), increased prevalence rates, and more women who need follow-up and survivorship care [1, 3, 4]. Primary care providers (PCPs) have always played an important role in the diagnosis phase of breast cancer care while oncologists and other specialists have managed patients' care during treatment and survivorship [5]. However, there is increasing awareness of the critical role of PCPs during the treatment and survivorship phases of care particularly given increased breast cancer prevalence and survival. This expanded role is supported by studies that have found that PCPs provide care for treatment

(c) The Author(s). 2019 Open Access This article is distributed under the terms of the Creative Commons Attribution 4.0 International License (http://creativecommons.org/licenses/by/4.0/), which permits unrestricted use, distribution, and reproduction in any medium, provided you give appropriate credit to the original author(s) and the source, provide a link to the Creative Commons license, and indicate if changes were made. The Creative Commons Public Domain Dedication waiver (http://creativecommons.org/publicdomain/zero/1.0/) applies to the data made available in this article, unless otherwise stated. 
toxicities and comorbid conditions during treatment, and follow-up care that is as safe as oncologist care that includes not just breast cancer and late effects follow-up but care for comorbid conditions and ongoing preventive care. Moreover, women have reported being very satisfied with follow-up care from PCPs $[6,7]$. To better understand the extent of PCP involvement in the care of breast cancer patients throughout the care continuum, we examined changes in the level of PCP utilization from prediagnosis to survival and inter-provincial variation across four Canadian provinces. We also examined factors associated with being a high user of primary care during prediagnosis, diagnosis, treatment, and survivorship.

\section{Methods}

\section{Design}

This study was conducted as part of a large, populationbased retrospective cohort study (the Canadian Team to Improve Community-Based Cancer Care along the Continuum - CanIMPACT) that examined health care use for women diagnosed with breast cancer using linked administrative health data from British Columbia $(\mathrm{BC})$, Manitoba (MB), Ontario (ON), and Nova Scotia (NS) [8]. Approvals were received from all relevant institutional research ethics boards (BC Cancer Agency/ University of British Columbia Research Ethics Board, University of Manitoba Health Research Ethics Board, Health Sciences and Affiliated Hospitals Research Ethics Board at Queen's University in Ontario, Nova Scotia Health Authority Research Ethics Board) as well as all relevant data access and privacy committees (BC Ministry of Health Chief Data Steward, MB Health's Health Information Privacy Committee, ICES-Queen's Privacy Office, NS Department of Health and Wellness Data Access Committee, Health Data Nova Scotia Data Access Committee). Due to provincial legislation and policy related to privacy issues, datasets were required to be analyzed separately within each province rather than being combined.

\section{Study population}

We included women $18+$ years of age who were diagnosed with stage I-III invasive breast cancer from 2007 to 2010 in $\mathrm{BC}$ or from 2007 to 2012 in $\mathrm{MB}, \mathrm{ON}$, and NS. The cohort was further restricted to women who had surgery plus adjuvant chemotherapy and were alive $30+$ months after diagnosis in order to follow-up women through their treatment and early survivorship $(N=19$, 589). Women were excluded if they did not have curative surgery (i.e., lumpectomy or mastectomy), were diagnosed with a new primary cancer or metastases in the first year after the breast cancer diagnosis date, were not eligible for provincial health insurance from diagnosis to the end of follow-up, or had a breast cancer recurrence within 2 years of diagnosis. Recurrence was defined as a second course of chemotherapy (chemotherapy initiated more than 3 months after the end of the last chemotherapy) or chemotherapy that began 1 year plus 90 days after surgery. Patients were censored at time of evidence of recurrence, diagnosed with a new primary cancer, death, or the study end date. The maximum follow-up time was 7.5 years. We did not exclude women who were on chemotherapy 1 year after diagnosis as this is the recommendation for Herceptin.

The following time phases were examined: prediagnosis (six to 30 months before diagnosis), diagnosis (0 to 6 months before diagnosis), treatment (start of chemotherapy to 6 months post chemotherapy initiation), and survivorship (four 12-month intervals beginning 12 months after diagnosis).

\section{Variables and data sources}

Detailed information about the CanIMPACT datasets and the source populations can be found in Groome et al. (2018) [9]. Briefly for this paper, provincial physician billing data were used to determine the number of PCP visits in each phase of care. Provincial cancer registries were used to identify the study cohort and provide information about date of diagnosis, stage, chemotherapy, postal code, and date of death. Provincial health insurance plan data provided demographic information (age, sex), date and type of surgery, and was used to determine comorbidity.

Age of diagnosis was separated into six groups (18-39, $40-49,50-59,60-69,70-74,75+$ ). Comorbidity was determined using the Johns Hopkins Aggregate Diagnosis Groups (ADGs) $(0-3,4-5,6-7,8+)$ [10]. Area of residence was determined using postal code and classified as rural, rural-remote, rural unknown, rural-very remote, and urban [11]. Statistics Canada 2006 census data were used to estimate household income (categorized into quintiles from Q1, the lowest income quintile to Q5, the highest income quintile) based on their dissemination area (DA) of residence as a proxy measure for individual-level income. Number of years since immigration was determined using the Canadian Immigration and Citizenship database and was available only for $\mathrm{ON}$ and $\mathrm{BC}$ (non-immigrant, $<5$ years, $5-10$ years, $>10$ years). In addition to number of visits as a measure of volume, a high user of primary care was defined based on the 90th percentile of the number of PCP visits at baseline weighted to the length of each phase.

\section{Statistical analysis}

Analyses were conducted in each province using centrally-developed SAS macros to ensure a standardized approach. A Generalized Estimating Equations (GEE) approach with an autoregressive [1] covariance 
structure to account for repeated measures was used. Negative binomial regression was used to compare the rate of PCP visits across the phases of care. The risk of being a high user of primary care was modelled using logistic regression.

\section{Results}

Table 1 shows the characteristics of the cohorts by province. The distribution of age and stage at diagnosis and income quintile were similar between provinces. A higher percentage of women in BC had low comorbidity (0 to $3,37.1 \%$ ) compared to other provinces (24-28\%). A higher percentage of women in MB (16\%) and NS (19.9\%) lived in a rural-very remote location compared to $\mathrm{BC}(6 \%)$ or $\mathrm{ON}(2.3 \%)$. The total number of PCP visits (i.e., not the total number of women) from pre-diagnosis to survival 4 years after diagnosis was 28,441 in $\mathrm{BC}, 8163$ in $\mathrm{MB}$, 69,302 in $\mathrm{ON}$, and 4664 in NS.
Table 2 shows the provincial variation in PCP use by phase of care compared to pre-diagnosis levels. PCP use during diagnosis was higher in $\mathrm{BC}, \mathrm{MB}$, and $\mathrm{ON}$ but lower in NS compared to pre-diagnosis. PCP use was higher during treatment compared to pre-diagnosis in all provinces. However, the difference was most pronounced in $\mathrm{BC}$ where $\mathrm{PCP}$ use was over six times higher during treatment. In all provinces, there was a general trend that PCP use was greatest during treatment and subsequently decreased with each successive survival year. In $\mathrm{BC}$, there was no difference in PCP use during survival year 1 compared to pre-diagnosis. PCP use during survival years 2,3 and 4 in $\mathrm{BC}$ was significantly lower compared to pre-diagnosis. $\mathrm{PCP}$ use was higher during survival years 1 and 2 in MB compared to prediagnosis with no difference in use during survival years 3 and 4. In ON, PCP use was higher during survival years 1,2 , and 3 with no difference during survival year 4 compared to pre-diagnosis. PCP use was significantly

Table 1 Characteristics of the cohort by province

\begin{tabular}{|c|c|c|c|c|c|}
\hline & & $\begin{array}{l}\text { British Columbia } \\
N=4133(\%)\end{array}$ & $\begin{array}{l}\text { Manitoba } \\
N=1472(\%)\end{array}$ & $\begin{array}{l}\text { Ontario } \\
N=12,851(\%)\end{array}$ & $\begin{array}{l}\text { Nova Scotia } \\
N=1133(\%)\end{array}$ \\
\hline \multirow[t]{6}{*}{ Age group } & $18-39$ & $276(6.7)$ & $130(8.8)$ & $1299(10.1)$ & $76(6.7)$ \\
\hline & $40-49$ & $1157(28.0)$ & $405(27.5)$ & $3302(25.7)$ & $330(29.1)$ \\
\hline & $50-59$ & $1412(34.2)$ & $514(34.9)$ & $4252(33.1)$ & $357(31.5)$ \\
\hline & $60-69$ & $1019(24.7)$ & $325(22.1)$ & 3059 (23.8) & $263(23.2)$ \\
\hline & $70-74$ & $189(4.6)$ & $68(4.6)$ & $610(4.7)$ & $53(4.7)$ \\
\hline & $75+$ & $80(1.9)$ & $30(2.0)$ & 329 (2.6) & $54(4.8)$ \\
\hline \multirow[t]{5}{*}{ Comorbidity } & $0-3$ & $1534(37.1)$ & $406(27.6)$ & 3584 (27.9) & $272(24.0)$ \\
\hline & $4-5$ & $1092(26.4)$ & $346(23.5)$ & $3126(24.3)$ & $263(23.2)$ \\
\hline & $6-7$ & $746(18.0)$ & $317(21.5)$ & $2832(22.0)$ & $230(20.3)$ \\
\hline & $8-9$ & $472(11.4)$ & 204 (13.9) & $1831(14.2)$ & $181(16.0)$ \\
\hline & $10+$ & $284(6.9)$ & $199(13.5)$ & $1478(11.5)$ & $187(16.5)$ \\
\hline \multirow[t]{3}{*}{ Stage at diagnosis } & । & $1083(26.2)$ & $344(23.4)$ & $2881(22.4)$ & $333(29.4)$ \\
\hline & $\|$ & $2182(52.8)$ & 775 (52.6) & $7332(57.1)$ & $568(50.1)$ \\
\hline & III & $868(21.0)$ & $353(24.0)$ & $2638(20.5)$ & $232(20.5)$ \\
\hline \multirow[t]{5}{*}{ Income quintile } & Q1 (lowest) & $744(18.0)$ & $191(13.0)$ & $2031(15.8)$ & 179 (15.8) \\
\hline & Q2 & 778 (18.8) & $267(18.1)$ & 2393 (18.6) & $218(19.3)$ \\
\hline & Q3 & $843(20.4)$ & $292(19.8)$ & $2536(19.7)$ & $235(20.8)$ \\
\hline & Q4 & $878(21.2)$ & $377(25.6)$ & $2839(22.1)$ & $263(23.3)$ \\
\hline & Q5(highest) & 835 (20.2) & $343(23.3)$ & $3011(23.4)$ & $236(20.9)$ \\
\hline \multirow[t]{4}{*}{ Area of residence } & Urban & 3593 (86.9) & $1071(72.8)$ & $11,249(87.5)$ & 795 (70.2) \\
\hline & Rural & $98(2.4)$ & $38(2.6)$ & $703(5.5)$ & $27(2.4)$ \\
\hline & Rural-remote & $176(4.3)$ & $124(8.4)$ & 597 (4.6) & $86(7.6)$ \\
\hline & Rural-very remote & $248(6.0)$ & $235(16.0)$ & $300(2.3)$ & 225 (19.9) \\
\hline $\begin{array}{l}\text { Total number of primary } \\
\text { care provider visits }\end{array}$ & & 28,441 & 8163 & 69,302 & 4664 \\
\hline
\end{tabular}

Notes: Comorbidity was measured using Aggregated Diagnostic Groups; $0.1 \%$ were missing comorbidity in $\mathrm{BC} ; 1.3 \%$ missing income quintile in $\mathrm{BC}$, $0.1 \%$ in $\mathrm{MB}$, $0.3 \%$ in $\mathrm{ON}$, and $<0.6 \%$ in NS; $0.4 \%$ missing area of residence in $\mathrm{BC}, 0.1 \%$ in $\mathrm{MB},<0.03 \%$ in $\mathrm{ON} ; 0 \%$ had a rural unknown residence in $\mathrm{BC}, \mathrm{ON}$, and $\mathrm{BC}$; $<0.7 \%$ had a rural unknown residence in MB. Total number of primary care provider visits determined using physician billing data for all phases of care 
Table 2 Variation in primary care provider utilization by phase of care and province (unadjusted)

\begin{tabular}{llllll}
\hline & & British Columbia & Manitoba & Ontario & Nova Scotia \\
& & RR $(95 \% \mathrm{Cl})$ & RR $(95 \% \mathrm{Cl})$ & RR $(95 \% \mathrm{Cl})$ & Ref \\
\hline Phase of care & Pre-diagnosis & Ref & Ref & $1.42(1.40-1.45)$ & $0.72(0.61-0.84)$ \\
& Diagnosis & $1.65(1.61-1.70)$ & $1.38(1.32-1.43)$ & $1.84(1.80-1.88)$ & $1.39(1.32-1.46)$ \\
& Treatment & 6.41 $(6.21-6.63)$ & $2.13(2.02-2.25)$ & $1.19(1.16-1.21)$ & $1.28(1.22-1.34)$ \\
& Survival Year 1 & $1.02(0.99-1.06)$ & $1.24(1.19-1.30)$ & $1.08(1.05-1.10)$ & $1.01(0.93-1.10)$ \\
& Survival Year 2 & $0.85(0.82-0.88)$ & $1.12(1.07-1.17)$ & $1.03(1.01-1.05)$ & $0.93(0.81-1.06)$ \\
& Survival Year 3 & $0.59(0.57-0.62)$ & $1.05(0.99-1.11)$ & $0.98(0.96-1.01)$ & $0.85(0.75-0.97)$ \\
\hline
\end{tabular}

Notes: RR - Relative Risk; $\mathrm{Cl}$ - Confidence interval

higher in NS during survival year 1 and significantly lower during survival year 4 compared to pre-diagnosis.

Table 3 shows the results of the analysis assessing the factors association with being a high user of primary care during treatment. The 90th percentile of the number of PCP visits at baseline was 15 visits for BC, 20 visits for NS, 19 visits for ON, and 20 visits for MB. Younger age was associated with lower odds of high PCP use in BC (age 40-49) and ON (age 18-59) relative to 60-69 year olds. In all provinces, a higher comorbidity score was associated with higher $\mathrm{PCP}$ use, and those with eight or more ADGs were consistently likely to be highest users of primary care. Income quintile was only associated with high $\mathrm{PCP}$ use in $\mathrm{MB}$ and $\mathrm{ON}$. In $\mathrm{MB}$, women who lived in areas with the second lowest income quintile $(\mathrm{Q} 2)$ were more likely to have high $\mathrm{PCP}$ use than those living in areas with the highest quintile (Odds Ratio (OR) 1.82; 95\% Confidence Interval (CI) 1.25-2.66). In ON, the likelihood of being a high PCP user decreased as income quintile increased. The likelihood of high PCP use increased with stage in BC and $\mathrm{MB}$, while in $\mathrm{ON}$, only those diagnosed with stage II cancers were more likely to have high PCP use compared to stage I. Women who lived in rural settings (i.e., rural, rural-remote, and rural-very remote) were more likely to be high PCP users compared to women who lived in urban areas in $\mathrm{BC}, \mathrm{MB}$, and $\mathrm{ON}$. In NS, only women in rural-very remote areas were more likely to be high PCP users compared to urban areas (OR 1.52, 95\% CI 1.05-2.20). Immigration was associated with high PCP use in BC but not in ON; women who had immigrated more than 10 years ago were less likely to be high PCP users compared to non-immigrants (OR 0.66, 95\% CI 0.51-0.85). Finally, women who were high PCP users in the pre-diagnosis phase were more likely to be high users during treatment in all provinces.

Results for the diagnosis phase (Additional file 1: Table S1) were similar to the treatment phase in that the odds of being a high primary care user increased as comorbidity increased in all provinces except NS. However, stage was only associated with high PCP use in $\mathrm{MB}$, as was income quintile and area of residence in $\mathrm{ON}$. Age was not associated with high PCP use during the diagnosis phase but immigration was in ON. Similarly, during the survivorship phases (Additional file 1: Tables S2 to S5), the odds of being a high primary care user increased as comorbidity increased (except BC and MB in year 4 and NS years 2, 3, and 4), and for high baseline use for all provinces and all years. A diagnosis of stage III breast cancer was associated with high $\mathrm{PCP}$ use in $\mathrm{BC}$ in survival years 1 and 2 and in $\mathrm{MB}$ during survival year 1 . Immigration was only associated with PCP use in ON, although not for all years or subgroups. Age, income quintile, and area of residence were not consistently associated with high PCP use, but where associations existed, younger women were less likely to have high PCP use than women 60-69 and women who lived in lower income areas were more likely to have high PCP use than those who lived in the highest income areas.

\section{Discussion}

We found that association of covariates with the likelihood of being a higher user of primary care varied between four Canadian provinces over the cancer care continuum for women diagnosed with stage I-III invasive breast cancer. The differences observed between provinces on the impact of different covariates on high PCP use may be related to differences in breast cancer screening program procedures and policies, differences in practice patterns during treatment, and differences in cancer agency and provincial recommendations regarding survivorship care. For example, differences observed between NS and other provinces in the association of various covariates with the likelihood of high PCP visits during the diagnosis phase of care may be related to the implementation of Nova Scotia Breast Screening patient navigators. Since 2000, a screening program navigator tracks and proactively facilitates further investigations for all women with imaging findings that require further testing, whether or not the women were screen detected or detected 
Table 3 Factors associated with being a high user of primary care during treatment

\begin{tabular}{|c|c|c|c|c|c|}
\hline & & $\begin{array}{l}\text { British Columbia } \\
(N=4078)\end{array}$ & $\begin{array}{l}\text { Manitoba } \\
(N=1467)\end{array}$ & $\begin{array}{l}\text { Ontario } \\
(N=12,672)\end{array}$ & $\begin{array}{l}\text { Nova Scotia } \\
(N=1131)\end{array}$ \\
\hline & & OR (95\% Cl) & OR (95\% Cl) & OR (95\% Cl) & OR (95\% Cl) \\
\hline \multirow[t]{6}{*}{ Age group } & 18-39 & $0.83(0.59-1.16)$ & $0.98(0.60-1.58)$ & $0.70(0.59-0.83)$ & $1.30(0.66-2.56)$ \\
\hline & $40-49$ & $0.75(0.61-0.94)$ & $0.83(0.59-1.17)$ & $0.81(0.72-0.91)$ & $1.45(0.94-2.25)$ \\
\hline & $50-59$ & $0.89(0.72-1.10)$ & $1.01(0.73-1.39)$ & $0.88(0.79-0.98)$ & $1.39(0.90-2.15)$ \\
\hline & $60-69$ & Ref & Ref & Ref & Ref \\
\hline & $70-74$ & $1.05(0.68-1.61)$ & $1.55(0.87-2.76)$ & $1.13(0.93-1.37)$ & $1.64(0.94-2.85)$ \\
\hline & $75+$ & $1.57(0.78-3.15)$ & $1.20(0.51-2.81)$ & $1.28(0.99-1.64)$ & \\
\hline \multirow[t]{4}{*}{ Comorbidity } & $0-3$ & Ref & Ref & Ref & Ref \\
\hline & $4-5$ & $1.43(1.18-1.72)$ & $1.03(0.73-1.46)$ & 1.19 (1.05-1.34) & $1.61(0.94-2.75)$ \\
\hline & $6-7$ & $1.44(1.15-1.79)$ & $1.24(0.87-1.75)$ & $1.47(1.30-1.66)$ & $2.26(1.33-3.82)$ \\
\hline & $8+$ & $2.63(1.98-3.49)$ & $1.59(1.12-2.26)$ & $2.03(1.80-2.29)$ & $3.93(2.41-6.40)$ \\
\hline \multirow[t]{5}{*}{ Income quintile } & Q1 (lowest) & $0.97(0.75-1.24)$ & $1.36(0.89-2.07)$ & $1.34(1.17-1.54)$ & $1.37(0.83-2.24)$ \\
\hline & Q2 & $1.06(0.83-1.36)$ & $1.82(1.25-2.66)$ & $1.28(1.12-1.46)$ & $0.75(0.45-1.26)$ \\
\hline & Q3 & $1.18(0.92-1.51)$ & $1.18(0.80-1.72)$ & $1.25(1.10-1.42)$ & $1.21(0.75-1.95)$ \\
\hline & Q4 & $0.80(0.63-1.00)$ & $1.14(0.79-1.62)$ & $1.17(1.03-1.33)$ & $1.32(0.83-2.08)$ \\
\hline & Q5 (highest) & Ref & Ref & Ref & Ref \\
\hline \multirow[t]{3}{*}{ Stage } & I & Ref & Ref & Ref & Ref \\
\hline & $\|$ & $1.20(1.01-1.44)$ & $1.43(1.05-1.94)$ & $1.12(1.01-1.25)$ & $1.07(0.75-1.52)$ \\
\hline & III & $1.56(1.24-1.97)$ & $1.50(1.05-2.15)$ & $1.09(0.96-1.24)$ & $0.81(0.52-1.28)$ \\
\hline \multirow[t]{4}{*}{ Area of residence } & Rural & $6.25(2.52-15.51)$ & $5.65(2.82-11.32)$ & $1.48(1.24-1.77)$ & $1.03(0.61-1.76)$ \\
\hline & Rural-remote & 7.60 (3.54-16.33) & $3.73(2.49-5.58)$ & $2.16(1.81-2.58)$ & \\
\hline & Rural-very remote & $4.46(2.65-7.48)$ & $5.26(3.83-7.21)$ & $4.08(3.20-5.22)$ & $1.52(1.05-2.20)$ \\
\hline & Urban & Ref & Ref & Ref & Ref \\
\hline \multirow[t]{4}{*}{ Number of years since immigration } & $<5$ years & $1.06(0.70-1.61)$ & NA & $0.98(0.73-1.32)$ & NA \\
\hline & $5-10$ years & $0.76(0.49-1.16)$ & NA & $0.88(0.66-1.16)$ & NA \\
\hline & $>10$ years & $0.66(0.51-0.85)$ & NA & $0.92(0.79-1.08)$ & NA \\
\hline & Non-immigrant & Ref & NA & Ref & NA \\
\hline \multirow[t]{2}{*}{ Baseline high user } & Yes & $2.22(1.47-3.37)$ & $4.13(2.63-6.48)$ & $3.00(2.63-3.43)$ & $2.74(1.73-4.34)$ \\
\hline & No & Ref & Ref & Ref & Ref \\
\hline
\end{tabular}

Notes: Comorbidity was measured using Aggregated Diagnostic Groups; OR - Odds Ratio; Cl - Confidence Interval

via a diagnostic mammogram. Because the navigator schedules all required imaging or biopsy appointments, women may be less likely to require a PCP visit. The navigator also provides women with informational and emotional support, which may also reduce a woman's need to see a PCP. MB and ON have also implemented direct referral processes for women with suspected breast cancer. In $\mathrm{MB}$, the screening program coordinates the first diagnostic test required after an abnormal screening mammogram and in $\mathrm{ON}$, a breast assessment site arranges the surgical consultation appointment for women with a positive biopsy for about $50 \%$ of patients during the era of this study [12]. Other health care system factors that could impact the effect of covariates on the odds of high PCP use during diagnosis include differing wait times or access to specialists or other health care resources.

Our study also found that while breast cancer patients continued to visit their PCP during treatment in all provinces, there was a higher relative rate of $\mathrm{PCP}$ visits in $\mathrm{BC}$. There may be various reasons for this observation including differences by province in how much PCPs are encouraged and supported to provide care for women during breast cancer treatment. Patient expectations and preferences may also be differ by province; generally, patients are increasingly consulting their PCP about treatment decisions $[13,14]$. In a recent study that included 517 women diagnosed with early stage breast cancer, Wallner at al. found that up to one-third of PCPs reported 
involvement in multimodal breast cancer treatment decisions [15]. Moreover, older PCPs and those who more positively evaluated their ability to participate in cancer treatment decision making were more likely to participate [15].

Care during diagnosis involves investigative tests and procedures to establish the diagnosis [16]. Care during treatment involves monitoring and treatment of acute adverse physical and psychological impacts of cancer therapy, and management of comorbid conditions [16]. Care during survivorship is related to routine follow-up for recurrence and on-going surveillance for late adverse events [16]. Although PCP use increased during diagnosis and treatment, visits decreased with each survival year in all four provinces. By survival year 2, PCP visits in BC were significantly lower than during pre-diagnosis. This may be related to issues of awareness, responsibility, or feasibility in providing specific follow-up care by patients and/or PCPs. A qualitative study in ON found that some PCPs believed that survivorship care was not their responsibility while others suggested that PCPs were ideally suited to provide care because of their on-going relationship with patients [17]. The challenges to providing survivorship care by PCPs have been well documented and include a lack of time, increased workload burden, inconsistent educational preparation, limited knowledge, provider anxieties, and patient preference for oncology-led follow-up care [18-22]. Factors that may increase PCP participation in survivorship care include experience leading to higher confidence in managing follow-up for breast cancer patients, support and clear direction from oncologists about follow-up expectations and how to deal with potential problems, and engaging PCPs early in the patient's cancer journey [5, 18, 23, 24]. Patient-specific survivorship care plans, which are endorsed by the American Society for Clinical Oncology and the Canadian Partnership Against Cancer, may also enhance the transition from specialist to PCP-provided care $[25,26]$.

The results of this study also highlight the factors that drive high primary care use in each phase of care and for each province. High comorbidity (8 or more ADGs) and baseline PCP use were important factors in all provinces for women who were alive at the start of the treatment phase of care. Therefore, women who had a greater need for care (e.g. due to comorbidity) prior to a diagnosis of breast cancer continued to have more $\mathrm{PCP}$ visits after diagnosis. Other important factors included advanced stage at diagnosis in $\mathrm{BC}$ and $\mathrm{MB}$, rural residence in $\mathrm{BC}$, $\mathrm{MB}, \mathrm{ON}$, and living in a lower income quintile in $\mathrm{ON}$. A higher stage at diagnosis often requires more complex care with more physician visits while individuals living in rural areas may see their PCPs more often because PCPs are more accessible than oncologists who primarily provide care in urban areas. Interestingly, age was not consistently associated with high primary care use across the phases of care; this may be due to the strong correlation between age and comorbidities. Finally, women who were high baseline users of primary care were also more likely to be high users in each subsequent phase of care.

Strengths of this study include the use of populationbased provincial cohorts that involved extensive work by the provinces to optimize data comparability. Despite this, we were unable to achieve optimum data analyses across provinces because of a lack of total data and file comparability $[9,27]$. However, this study adds to the discussion of both the value and complexities of comparative analysis of health systems with the intention of encouraging appropriate data collection and linkage for similar health system-level studies in other jurisdictions [28].We did not examine potential barriers to primary care use. However, the Canada's national health insurance program ensures that a lack of health insurance is not a barrier to care. Instead, morbidity is a major driver of high health care use [29]. Other potential barriers to care include not having a PCP $(15.5 \%$ of Canadians reported that they did not have a PCP in 2017) [30], lower levels of income [31, 32], or issues related to health literacy [33].

\section{Conclusions}

PCPs have traditionally been involved in the diagnosis phase of care; care during treatment and survivorship was seen as the responsibility of oncologists. However, we found that PCPs are involved in the care of women diagnosed with breast cancer throughout all phases of care and highest during treatment. Across the four provinces in this study, PCP use was higher during the diagnosis and treatment phases of care and early survivorship compared to pre-diagnosis and decreased in each successive survivorship year. In addition, women with comorbidities and those who were higher users of primary care prior to their cancer diagnosis were more likely to become high user of primary care during treatment. However, there were differences between the provinces; these variations in $\mathrm{PCP}$ use indicate potential practice and system-level opportunities to improve care for women diagnosed with breast cancer in Canada.

\section{Supplementary information}

Supplementary information accompanies this paper at https://doi.org/10. 1186/s12875-019-1052-2.

\footnotetext{
Additional file 1: Table S1. Factors associated with being a high user of primary care services during the diagnosis phase of care. Table S2. Factors associated with being a high user of primary care services during survival year 1. Table S3. Factors associated with being a high user of primary care services during survival year 2. Table S4. Factors associated with being a high user of primary care services during survival year 3 . Table S5. Factors associated with being a high user of primary care services during survival year 4 .
} 


\section{Abbreviations}

ADG: Aggregate Diagnosis Groups; BC: British Columbia; Cl: Confidence Interval; DA: Dissemination Area; GEE: Generalized Estimating Eqs:; MB: Manitoba; NS: Nova Scotia; ON: Ontario; OR: Odds Ratio; PCP: Primary Care Provider; Q1: Quintile 1; Q2: Quintile 2; Q3: Quintile 3; Q4: Quintile 4; Q5: Quintile 5; RR: Risk Ratio

\section{Acknowledgements}

The authors thank Dongdong Li for conducting statistical analyses in British Columbia. The authors would also like to thank ICES, a non-profit institution funded by an annual grant from the Ontario Ministry of Health and LongTerm Care (MOHLTC) and Cancer Care Ontario (CCO) which provided data and information. The opinions, results, view, and conclusions reported in this paper are those of the authors and do not necessarily reflect those of ICES, the Ontario MOHLTC, or CCO; no endorsement, ICES, the Ontario MOHLTC, or CCO is intended or should be inferred. We gratefully acknowledge the data and information compiled and provided by the Canadian Institute for Health Information (CIHI). However, the analyses, conclusions, opinions and statements expressed herein are those of the author, and not necessarily those of $\mathrm{CIHI}$. We gratefully acknowledge CancerCare Manitoba for their ongoing support and Manitoba Health for the provision of data. The results and conclusions presented are those of the authors and no official endorsement by Manitoba Health is intended or should be inferred. We also thank Health Data Nova Scotia and the Nova Scotia Department of Health and Wellness for the provision of data. The observations and opinions expressed are those of the authors and do not represent those of either Health Data Nova Scotia or the Department of Health and Wellness. Lastly, we gratefully acknowledge the data provided by Population Data BC and the BC Cancer Agency. All inferences, opinions, and conclusions drawn in this study are those of the authors, and do not reflect the opinions or policies of the BC Data Steward(s).

\section{Author's contribution}

$K D, C K, R U, P G, M M, M W$, and $E G$ contributed to the design of the work, the interpretation of the data, drafted and revised the manuscript, approved the submitted version of the manuscript, and agrees to be personally accountable for her contribution and to ensure that questions related to the accuracy or integrity of any part of the work, even ones in which she was not personally involved, are appropriately investigated, resolved, and the resolution documented in the literature. NB, RM, and MW (Queen's University) contributed to the acquisition and analysis of data, revised the manuscript, approved the submitted version of the manuscript, and agrees to be personally accountable for her contribution and to ensure that questions related to the accuracy or integrity of any part of the work, even ones in which she was not personally involved, are appropriately investigated, resolved, and the resolution documented in the literature. All authors have read and approved the manuscript.

\section{Funding}

Funding for this study was provided by the Canadian Institutes of Health Research (CIHR; grant 128272) and the Canadian Centre for Applied Research in Cancer Control, funded by Canadian Cancer Society (grant \#2015-703549). The funding agencies had no role in the design of the study and collection, analysis, and interpretation of the data or in the writing of the manuscript.

\section{Availability of data and materials}

The data that support the findings of this study are not publically available to ensure and maintain the privacy and confidentiality of individuals' health information. Requests for may be made to the data stewards in each province (BC Ministry of Health Chief Data Steward, MB Health's Health Information Privacy Committee, ICES-Queen's Privacy Office, NS Department of Health and Wellness Data Access Committee, Health Data Nova Scotia Data Access Committee) but restrictions apply to the availability of these data, which were used under license for the current study, and so are not publicly available.

\section{Ethics approvals and consent to participate}

Approvals were received from all relevant institutional research ethics boards (BC Cancer Agency/University of British Columbia Research Ethics Board, University of Manitoba Health Research Ethics Board, Health Sciences and Affiliated Hospitals Research Ethics Board at Queen's University in Ontario, Nova Scotia Health Authority Research Ethics Board) as well as all relevant data access and privacy committees (BC Ministry of Health Chief Data Steward, MB Health's Health Information Privacy Committee, ICES-Queen's Privacy Office, NS Department of Health and Wellness Data Access Committee, Health Data Nova Scotia Data Access Committee).

\section{Consent for publication}

Not applicable.

\section{Competing interests}

The authors declare that they have no competing interests.

\section{Author details}

${ }^{1}$ CancerCare Manitoba, 675 McDermot Avenue, Winnipeg, Manitoba ROE OV9, Canada. ${ }^{2}$ University of Manitoba, 750 Bannatyne Avenue, Winnipeg, Manitoba R3E OW2, Canada. ${ }^{3}$ University of Toronto, 500 University Avenue, Toronto, Ontario M5G 1V7, Canada. ${ }^{4}$ Dalhousie University, 1276 South Park Street, Halifax, Nova Scotia B3H 2Y9, Canada. ${ }^{5}$ Nova Scotia Health Authority, 1276 South Park Street, Halifax, Nova Scotia B3H 2Y9, Canada. ${ }^{6}$ Queen's University, 62 Fifth Field Company Lane, Kingston, Ontario K7L 3N6, Canada. ${ }^{7}$ BC Cancer Agency, 686 West Broadway, Suite 500, Vancouver, British Columbia V5Z 1G1, Canada. ${ }^{8}$ Stanford University, 1265 Welch Road, Stanford, California 94305, USA. ${ }^{9}$ Ontario Institute for Cancer Research, 661 University Avenue, Suite 510, Toronto, Ontario M5G 0A3, Canada.

\section{Received: 18 July 2019 Accepted: 15 November 2019}

Published online: 21 November 2019

\section{References}

1. Canadian Cancer Statistics Advisory Committee. Canadian Cancer Statistics 2018. Toronto; 2018.

2. Carioli G, Malvezzi M, Rodriguez T, Bertucio P, N E, La Vecchia C. Trends and predictors to 2020 in breast cancer mortality: Americas and Australiasia. Breast. 2018:37:163-9.

3. Allemani C, Matsuda T, Di Carlo V, Harewood R, Matz M, N M, et al. Global surveillance of trends in cancer survival 2000-14 (CONCORD-3): analysis of individual records for 37513025 patients diagnosed with one of 18 cancers from 322 population-based registries in 71 countries. Lancet. 2018; 391(10125):1023-75.

4. Canadian Cancer Statistics Advisory Committee. Canadian Cancer Statistics 2017. Toronto, ; 2017.

5. Chaput G, Sussman J. Integrating primary care providers through the seasons of survivorship. Curr Oncol. 2019;26(1):48-54.

6. Grunfeld E, Levine M, Julian J, Coyle D, Szechtman B, Mirsky D, et al. Randomized trial of long-term follow-up for early-stage breast cancer: a comparison of family physicans versus specialist care. J Clin Oncol. 2006; 24(6):848-55.

7. Grunfeld E, Fitzpatrick R, Mant D, Yudkin P, Adewuyi-Dalton R, Stewart J, et al. Comparison of breast cancer patient satisfaction with follow-up in primary care versus specialist care: results from a randomized controlled trial. Br J Gen Pract. 1999:49(446):705-10.

8. Grunfeld E, Petrovic B. Consultative workshop proceedings of the Canadian team to improve community-based cancer care along the continuum. Curr Oncol. 2017;24(2):135-40.

9. Groome PA, ML MB, Jiang L, Kendell C, Decker KM, Grunfeld E, et al. Lessons learned: it takes a villiage to understand inter-sectoral care using administrative data across jurisdictions. Int J Pop Data Science. 2018;3(3):1-12.

10. The Johns Hopkins University Bloomberg School of Public Health, Health Services Research Development Center. The Johns Hopkins ACG System. Installation and Usage Guide. Version 9.0. Baltimore: Johns Hopkins University Bloomberg School of Public Health; 2009.

11. Wilkins R. PCCF+ Version 5K Users Guide (Geocodes/PCCF).Automated Geographic Coding Based on the Statistics Canada .Postal Code Conversion Files, Including Postal Codes to May 2011 (Catalogue 82F0086-XDB). Ottawa; 2012.

12. Jiang L, Gilbert J, Langley H, Moineddin R, Groome PA. Breast cancer detection method, diagnostic interval, and use of specialized diagnostic assessment units in Ontario, Canada. Health Promot Chronic Dis Prev Can. 2018;38(10):358-67.

13. Levit LA, Balogh EP, S.J. N, Ganz PA. Delivering high-quality caner care: charting a new course for a system in crisis. Washington, DC: National Academies Press; 2013. 
14. Cohen HJ. A model for the shared care of elderly patients with cancer. Am J Geriatr Soc. 2009;57(suppl 2):S300-S2.

15. Wallner LP, Li Y, McLeod MC, Gargaro J, Kurian AW, Jagsi R, et al. Primary care provider-reported involvement in breast cancer treatment decisions. Cancer. 2019;0:1-8.

16. Rubin G, Berendsen A, Crawford SM, Dommett R, Earle C, Emery J, et al. The expanding role of primary care in cancer control. Lancet Oncol. 2015;12: 1231-72.

17. Luctkar-Flude M, Aiken A, McColl MA, Tranmer J. What do primary care providers think about implementing breast cancer survivorship care? Curr Oncol. 2018;25(3):196-205.

18. Neuman HB, Jacobs EA, Steffens NM, Jacobson N, Tevaarwerk A, Wilke LG, et al. Oncologists' perceived barriers to an expanded role for primay care in breast cancer survivorship care. Cancer Med. 2016;5(9):2198-204.

19. Tucholka JL, Jacobson N, Steffens NM, Schumacher JR, Tevaarwerk AJ, Anderson B, et al. Breast cancer survivors's perceptions on the role different providers play in follow-up care. Support Care Cancer. 2018;26(6):2015-22.

20. Murchie P, Norwood PF, Pietrucin-Materek M, Porteous T, Hannaford PC, Ryan M. Determining cancer survivors' preferences to inform new models of follow-up care. Br J Cancer. 2016;115(12):1495-503.

21. Hugh-Yeun K, Kumar D, ., Moghaddamjou A, Ruan JY, Cheung WY. Young adult cancer survivors' follow-up care expectations of oncologists and primary care physicians. J Cancer Surviv 2017;11(3):295-301.

22. Hudson SV, Ohman-Strickland PA, Bator A, O'Malley D, Gundersen D, Lee $H S$, et al. Breast and prostate cancer survivors' experiences of patientcentered cancer follow-up care from primary care physicians and oncologists. J Cancer Surviv. 2016;10(5):906-14.

23. Smith SL, Wai ES, Alexander C, Singh-Carlson S. Caring for survivors of breast cancer: perspectives of the primary care physician. Curr Oncol. 2011; 18:e218-e26.

24. O'Brien MA, Grunfeld E, Sussman J, Porter G, Mobilio MH. Views of family physicians about survivorship care plans to provide breast canccer followup: exploration of results from a randomized controlled trial. Curr Oncol. 2015;22:252-9.

25. McCabe MS, Bhatia S, Oeffinger KC, Reaman GH, Tyne C, Wollins DS, et al. American Society of Clinical Oncology statement: achieving high-quality cancer survivorship care. J Clin Oncol. 2013:31 (5):631-40.

26. Daudt HML. vanMossel C, Dennis DL, Leitz L, Watson HC, Tanliao JJ. Survivorship care plans: a work in progress. Curr Oncol. 2014;21:e466-e79.

27. Kendell C, Decker KM, Groome PA, McBride ML, Jiang L, Krysanowska MK, et al. Use of physician services during the survivorship phase: a multiprovince study of women diagnosed with breast cancer. Curr Oncol. 2017; 24(2):81-9.

28. Lipscomb J, Yabroff KR, Hornbrook MC, Gigli A, Francisci S, Krahn M, et al. Comparing care, outcomes, and costs across health systems: charting the course. J Natl Cancer Inst Monogr. 2013;46:124-30.

29. Reid R, Evans R, Barer M, Sheps S, Kerluke K, McGrail K, et al. Conspicuous consumption: characterizing higher users of physician services in one Canadian province. J Health Serv Res Policy. 2003;8(4):215-24.

30. Canada S. Primary health care providers, 2017: Ottawa, Statistics Canada: 2019. [Available from: https://www150.statcan.gc.ca/n1/pub/82-625-x/20 9001/article/00001-eng.htm

31. Decker KM, Demers AA, Nugent Z, Biswanger N, Singh H. Longitudinal rates of colon cancer screening use in Winnipeg, Canada: the experience of a universal health care system with an organized colon screening program. Am J Gastroenterol. 2015;1 10(12):1640-6. https://doi.org/10.1038/ajg.2015.206.

32. Decker KM, Demers AA, Nugent Z, Biswanger N, Singh H. Reducing incomerelated inequities in colorectal cancer screening: lessons learned from a retrospective analysis of organised programme and non-programme screening delivery in Winnipeg. Manitoba BMJ Open. 2016;6:e009470.

33. Lofters A, McBride ML, Li D, Whitehead M, Moineddin R, Jiang L, et al. Disparities in breast cancer diagnosis for immigrant women in Ontario and BC: results from the CanIMPACT study. BMC Cancer. 2019;19(42):1-11.

\section{Publisher's Note}

Springer Nature remains neutral with regard to jurisdictional claims in published maps and institutional affiliations.

\section{Ready to submit your research? Choose BMC and benefit from}

- fast, convenient online submission

- thorough peer review by experienced researchers in your field

- rapid publication on acceptance

- support for research data, including large and complex data types

- gold Open Access which fosters wider collaboration and increased citations

- maximum visibility for your research: over $100 \mathrm{M}$ website views per year

At BMC, research is always in progress.

Learn more biomedcentral.com/submissions 